\title{
EVALUATION OF DENTAL ANXIETY OF CHILD AND PARENT DURING DENTAL TREATMENT: “OBSERVATIONAL STUDY"
}

\author{
Dalia Abd Elmonaem Ibrahem*, Norhan Abd Elwahab El Dokky** and Samah Mohamed Awad**
}

\begin{abstract}
This study is an observational study aimed to evaluate children dental anxiety during treatment.

Subjects and methods: The dental anxiety degree of 200 children, 100 males \& 100 females with age range of 3-6 years old (mean age $=4.8$ ) who had primary tooth indicated for extraction was assessed using Venham Picture Test. In this study the children neither had any previous visits to a dentist nor did they have any history of any systemic disease nor hospitalization. Children were selected from outpatient's clinics of Pediatric Dentistry and dental public health department Faculty of Oral and Dental Medicine - Cairo University.
\end{abstract}

Result: The study comprised of 100 males (mean age $=4.88, \mathrm{SD}=0.13$ ) and 100 females (mean age $=4.85, \mathrm{SD}=0.12$ ). Statistical analysis revealed no significant difference in age between males and females ( $\mathrm{p}$-value $=0.233$ ). In the present study Venham Picture Test was used to assess children's dental anxiety at different times during dental treatment. An insignificant difference between males and females for all questions was noted.

Conclusion: No significant difference in age between males and females was found. Gender has no impact on the dental anxiety. Regarding children, the highest anxiety provoking situations were taking anesthesia injection. While the lowest anxiety provoking situations were at waiting room.

KEY WORDS: Dental Anxiety-Venham Picture Test

\section{INTRODUCTION}

Dental anxiety is a common phenomenon in pediatric dentistry, it affects the child cooperation in dental clinic leading to difficult or even impossible treatment. The behavior of anxious children during treatment may even interfere with prognosis and may negatively influence the relationship between dentist, parents and patient. Further anxious fearful children may tend to avoid dental treatment. Which may exacerbate the problem, interfere with oral health, eating and even sleeping (Gao et al., 2013). It is important that dentists are able to assess dental

* MSc in Pediatric Dentistry.

** Associate Professor of Pediatric Dentistry, Faculty of Oral and Dental Medicine, Cairo University. 
anxiety in children as early as possible, so that they may identify patients who are in special need with regards to their fear (Shinohara et al., 2005). For this purpose, formal assessment measures are essential. There are various assessment methods available, however, the ideal measure should be valid, allow for limited cognitive and linguistic skills, and be easy to administer and preferably score in a clinical context (Buchanan \& Niven, 2002).

Many questionnaires have been developed to measure dental anxiety and fear (Armfield, 2010; Schuurs \& Hoogstraten, 2010). Venham Picture Test (VPT) is one of the few picture scales that fulfills the required criteria to assess dental anxiety in children (Venham, 1979) and has been used in a number of studies to assess anxiety (Agarwal \& Das, 2013).

Many variables affect the conquest of dental anxiety and fear such as gender, age, socioeconomic state, type of procedure, previous dental experience, dentist attitude toward child and parents. It is suggested that parents are one of the most important variables that determines the child attitude and dental fear because of their role in personal trait development. Therefore, parents' attitudes towards dental treatment might be reflected on their child behavior positively or negatively in dental clinic to the extent that it is a controversial issue to allow the parents to be with the child during treatment or not. It must be noted that parental dental fear has an effect on the child's dental fear (Molinari \& Deyoung, 2004; Chen-Yi et al., 2008; ThemesselHuber et al., 2010).

\section{MATERIAL AND METHODS}

This study is an observational study. The ethical clearance of this study was availed from the Committee of Ethics at Faculty of Oral and Dental Medicine, Cairo University.

\section{Study sample:}

The study was carried out on (200) chil- dren aged 3-6 years old (mean age $=4.8$ ) who had primary tooth indicated for extraction and their parent. Children were selected from outpatient's clinics of Pediatric Dentistry and dental public health department, Faculty of Oral and Dental Medicine, Cairo University.

The study sample was calculated statistically using StatsToDo software, where the expected meaningful correlation between the scores obtained on the different anxiety scales of child and parent ranged from a very weak $\mathrm{r}=0.21$ to good correlation $r=0.64$. A total sample size of 14 children was sufficient for a correlation $\mathrm{r}=0.64$ to be significant. In order for the value of the correlation $r=0.21$ to be significant a total sample size of 139 children was needed. This number been increased again to a total sample size of 200 children, to allow for losses of around 25\%. Allan Chang (Brisbane, Queensland, Australia).

\section{Criteria of Selection:}

\section{A-Inclusion criteria:}

Children who met the following inclusion criteria were selected to participate in the study:

1. Children aged 3-6 years old.

2. Communicative children.

3. Patient with primary tooth indicated for extraction.

4. The absence of any systemic diseases.

5. No history of previous hospitalization.

6. Lacking any experience of harmful accidents.

\section{B-Exclusion criteria:}

Children who met the following exclusion criteria were excluded from the study:

1. Patients who were unable to provide complete answers to the questionnaires.

2. History of social or specific phobia. 
3. History of dental visits.

4. History of previous dental pain.

5. Lacking of dental problems requiring treatment.

The study was carried out on (200) children aged 3-6 years old (mean age=4.8). Each patient in the current study, was diagnosed to undergo molar extraction after having inferior alveolar nerve block anesthesia. (Arnrup et al., 2003).

The researcher verbally translated the questions into Arabic language and filled out the questionnaires by interviewing the child and explaining each point to them. To assess children dental anxiety and fear, the questionnaires were admitted to children separately from their parents to avoid their influence.

At first, Venham Pictures Test was used, where cards were admitted to the child at different times during the dental visit in successive situations (1at waiting room, 2-immediately before seating on the dental chair, 3-immediately after seating on the dental chair, 4-before having inferior alveolar nerve block anesthesia, 5-after taking anesthetic injection, 6-before tooth extraction, 7-after tooth extraction, 8 -immediately after leaving dental chair).

The instructions were as follows, "I have some pictures. I want you to pick the boy who feels the most like you feel right now. Look carefully at their faces to see how they feel".

\section{RESULTS}

\section{Demographic data}

The study comprised of 100 males (mean age $=4.88, \quad \mathrm{SD}=0.13$ ) and 100 females (mean age $=4.85, \mathrm{SD}=0.12$ ). Statistical analysis revealed no significant difference in age between males and females ( $p$-value $=0.233$ ).

\section{Venham Pictures Test}

In the present study Venham Pictures Test was used to assess children's in at different times during dental treatment. An insignificant difference between males and females for all questions was noted.

It was found that the highest percentage of anxiety was recorded after anesthetic injection (61\% males \& $68 \%$ females) and before tooth extraction (63\% males \& $68 \%$ females). While the lowest percentage of anxiety was recorded at waiting room ( $2 \%$ males \& $8 \%$ females), it has to be noted that the number of males reported being anxious at waiting room was higher than the number of females.

At waiting room; males $(79 \% \mathrm{n}=79)$ answered 0 and $(21 \% \mathrm{n}=21)$ answered 1 . This showed an insignificant difference compared to females where $(92 \% n=92)$ answered 0 and $(8 \% n=8)$ answered 1 (p-value $=0.078)$.

Immediately before seating on the dental chair; males $(75 \% n=75)$ answered 0 and $(25 \% n=25)$ answered 1 . This showed an insignificant difference compared to females where $(84 \% \mathrm{n}=84)$ answered 0 and $(16 \% \mathrm{n}=16)$ answered $1(\mathrm{p}$-value $=0.295)$.

Immediately after seating on the dental chair; males $(67 \% n=67)$ answered 0 and $(33 \% n=33)$ answered 1 . This showed an insignificant difference compared to females where $(74 \% \mathrm{n}=74)$ answered 0 and $(26 \% \mathrm{n}=26)$ answered $1(\mathrm{p}$-value $=0.469)$.

Before taking anesthetic injection; males (74\% $\mathrm{n}=74)$ answered 0 and $(26.5 \% \mathrm{n}=26)$ answered 1 . This showed an insignificant difference compared to females where $(70 \% \mathrm{n}=70)$ answered 0 and $(30 \%$ $\mathrm{n}=30)$ answered $1(\mathrm{p}$-value $=0.703)$.

After taking anesthetic injection; males (39\% $\mathrm{n}=39)$ answered 0 and $(61 \% \mathrm{n}=61)$ answered 1 . This showed an insignificant difference compared to females where $(32 \% \mathrm{n}=32)$ answered 0 and $(68 \%$ $\mathrm{n}=68)$ answered $1(\mathrm{p}$-value $=0.483)$.

Before tooth extraction; males $(37 \% \mathrm{n}=37)$ answered 0 and $(63 \% n=63)$ answered 1 . This showed an insignificant difference compared to females where $(32 \% \mathrm{n}=32)$ answered 0 and $(68 \% \mathrm{n}=68)$ answered $1(\mathrm{p}$-value $=0.622)$. 
After tooth extraction; males $(65 \% \mathrm{n}=65)$ answered 0 and $(35 \% \mathrm{n}=35)$ answered 1 . This showed an insignificant difference compared to females where $(48 \% \mathrm{n}=48)$ answered 0 and $(52 \%$ $\mathrm{n}=52)$ answered 1 ( $\mathrm{p}$-value $=0.084)$.

Immediately after leaving dental chair; males $(83 \% \mathrm{n}=83)$ answered 0 and $(17 \% \mathrm{n}=17)$ answered 1 . This showed an insignificant difference compared to females where $(74 \% \mathrm{n}=74)$ answered 0 and $(26 \%$ $\mathrm{n}=26)$ answered 1 ( $\mathrm{p}$-value $=0.242)$.

\section{DISCUSSION}

Venham Picture Test was used to evaluate children dental anxiety as it is easy to apply on children and does not take much time of child as well as dentist. The advantage of this scale is not only its clarity and reliability but also its ease of recording (Prabhakar et al., 2007).

According VPT statistical analysis showed that the highest percentages of anxiety were recorded after anesthetic injection. This comes in accordance with study encountered by Hembrecht et al., 2013. This suggests that invasive procedures cause greater anxiety in children. Also, the psychological perception of anesthetic injection and dental extraction as a potential harmful situation might provoke dental anxiety.

On the other hand, the lowest percentage of anxiety was recorded at waiting room. This supports results found in previous study Rahul \& Lalwah, 2010. This might be because of the fact that the child had no knowledge regarding the treatment they would undergo and had no previous dental history. Also, distraction offered by videotaped cartoons played at waiting room might had decreased children anxiety.

\section{CONCLUSIONS}

1. Gender has no impact on the dental anxiety.

2. The highest anxiety provoking situations were taking anesthesia injection. While the lowest anxiety provoking situations were at waiting room.

\section{REFERENCES}

- Agarwal M, Das UM. Dental anxiety prediction using Venham Picture test: A preliminary cross-sectional study; 31(1): 22-24. 2013.

- $\quad$ Arnrup, K., Broberg, A. G., Berggren, U., \& Bodin, L. Treatment outcome in subgroups of uncooperative child dental patients: an exploratory study. International Journal of Paediatric Dentistry / the British Paedodontic Society [and] the International Association of Dentistry for Children, 13(5), 304-319. 2003.

- Buchanan H, Niven N. Validation of a Facial Image Scale to assess child dental anxiety. Int J Paediatr Dent.; 12(1): 47-52. 2002

- $\quad$ Chen-Yi Lee, Yong-Yuan Chang, Shun-Te Huang. The clinically related predictors of dental fear in Taiwanese children. Int J Paed Dent; 18:415-422. 2008.

- Gao, X., Hamzah, S. H., Yiu, C. K. Y., McGrath, C., \& King, N. M. Dental fear and anxiety in children and adolescents: qualitative study using YouTube. Journal of Medical Internet Research, 15(2), e29. doi:10.2196/ jmir.2290. 2013.

- Hembrecht EJ, Nieuwenhuizen J, Aartman IHA, Krikken J, Veerkamp JSJ. Pain-related behaviour in children: a randomized study during two sequential dental visits. Eur Arch Paediatr Dent. ; 14:3-8. 2013.

- Molinari BGE, Deyoung A. Parental Presence and absence as a behavior management technique. J MICH Dent Assoc.; 86(1):30-33. 2004.

- Prabhakar AR, Marwah N, Raju OS. A comparison between audio and audio visual distraction technique in managing anxious pediatric dental patients. J Indian Soc Pedod Prevent Dent. ; 25(4):177-182. 2007.

- $\quad$ Rahul S, Lalwah S L. Dental Anxiety in a Sample of West Indian Adults. The West Indian medical journal; 59(5):567572. 2010 .

- $\quad$ Shinohara S ,Nomura Y, Shingyouchi K, Takase A, Ide M, Moriyasu K, Idaira Y, Takahashi T, Yamada Y, Aoyagi Y, Asada Y. Structural relationship of child behavior and its evaluation during dental treatment. J Oral Sci; 47(2):9196. 2005

- Themessl-Huber M,Freeman R,Humphris G,MacGillivray $\mathrm{S}$, Terzi N. Empirical evidence of the relationship between parental and child dental fear: a structured review and meta-analysis. Int J Paediatr Dent. ; 20(2):83-101. 2010.

- Venham LL. The effect of mother's presence on child's response to dental treatment. ASDC J Dent Child; 46(3): 219-225. 1979. 